\title{
302 摩擦伝動ベルトの伝達性能予測（DWによる張力付与方式）
}

\section{Prediction Method of Performance for a Frictional Power Transmission Belt (in case of DW).}

正 ○大倉 清（三ツ星ベルト）橋本康弘（三ツ星ベルト）

Kiyoshi OKURA, Mitsuboshi Belting Ltd, 1-21, 4-Chome, Hamazoe-dori, Nagata-ku, Kobe

Yasuhiro HASHIMOTO, Mitsuboshi Belting Ltd

Performance for a frictional power transmission belt such as flat or V-ribbed belts is usually obtained by experiments using two pulleys system for instance and expressed as torque or horsepower of driven axis at the $2 \%$ slip ratio. On the other hand few theoretical studies on the performance have been reported. We have already reported theoretical prediction method of the performance in which tension is set up by fixed pulley. In this paper, a formula to predict the performance in case of tension set up by dead weight (DW) is introduced. Then, validities of the formula are verified by experiments and finally comparison of the performance between fixed pulley system and DW system is described.

Key Words : Transmission Performance, Effective Tension, Friction Coefficient, Slip Ratio, Pulley Layout

\section{1. まえがき}

平ベルト，Vリブドベルト等の円筒プーリを介して動力を 伝達する摩擦伝動ベルトの伝達性能は図 1 に示すような 2 軸 システム等を用いた試験により求められ，例えば $2 \%$ スッ プ時における従動軸トルク，従動軸馬力等により表現される のが一般的であり (1)，伝達性能に関する理論面での検討は殆 ど為されていない，筆者等は既にプーリ軸固定による張力付 与方式の場合について, 初期設定張力と走行時の各スパン張 力の関係式をべースに伝達性能予測式を誘導すると共に，そ の妥当性について検討済みである(2),(3). 本稿ではデッドウ エイト（DW）による張力付与方式の場合の伝達性能につい て，理論と実験の両面での検討結果について述べる，更に， プーリ固定方式と DW方式の伝達性能の比較検討結果につ いても報告する.

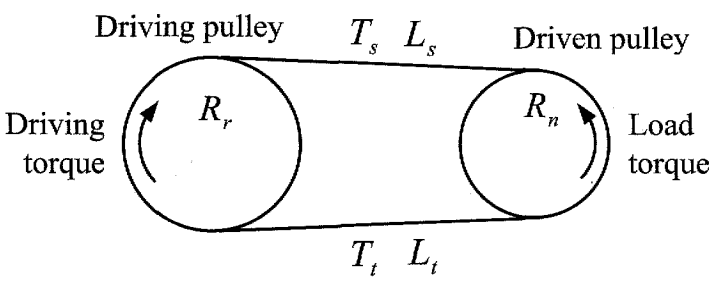

Fig.1 Two axis model of belt driving system

\section{2. 伝達性能の理論と特徵}

\subsection{DWを緩夕側に配置した場合}

図 2 に示すレイアウトに置いてアイドラープーリ Id 軸を フリーにし，これに錘Wを掛けて張力を付与するDW方式の 場合の伝達性能について検討する。図 2 において，停止時に 対する走行時のベルト伸び，これに伴う巻き付け角等の変化

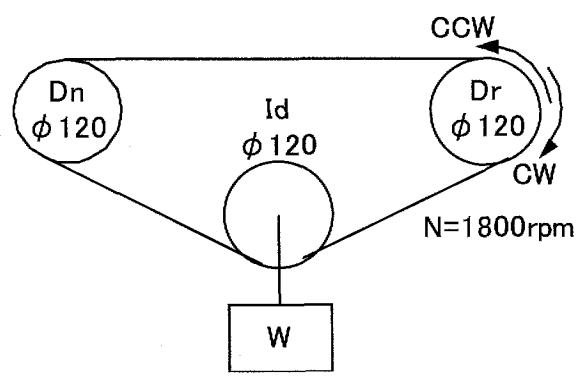

Fig.2 Experimental layout (in case of DW)
率は非常に小さく無視出来ることから，レイアウトは不変と 見なせる。図 2 において，駆動軸を時計回り（CW）に回転さ せるとDWは緩み側配置となるが，この時，張り側，緩み側 の張力比は次式で与えられる.

$$
T_{t} / T_{0}=e^{\mu \phi}
$$

ここで， $T_{t}$ は張り側張力， $T_{0}$ はDWによって決まる緩み側 張力（一定）であり， $\mu$ は摩擦係数， $\phi$ は滑り角である. また，プーリに作用する有效張力 $T_{e}$ は次式で定義される.

$$
T_{e}=T_{t}-T_{0}
$$

ここで， $\theta_{r} \geq \theta_{n}$ として負荷トルクを徐々に上げていく時，

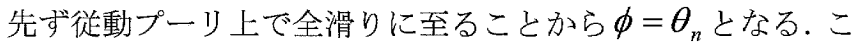
の時, 従動プーリ上で全滑りに至った時点の有効張力で定義 する最大有効張力が式(1)，式(2)により次式のように求めら れる. 既報告で述べたように, この最大有効張力が試験で得 られる伝達性能に対応する。

$$
T_{e}^{*}=\left(e^{\mu \theta_{n}}-1\right) T_{0}
$$

式(3)による最大有効張力を巻き付け角, 摩擦係数をパラメ 一タに取り計算した結果を図 3 に示すが，式(3)からも明ら かなように最大有効張力は巻き付け角, 摩擦係数に対して指 数関数的に増加する.

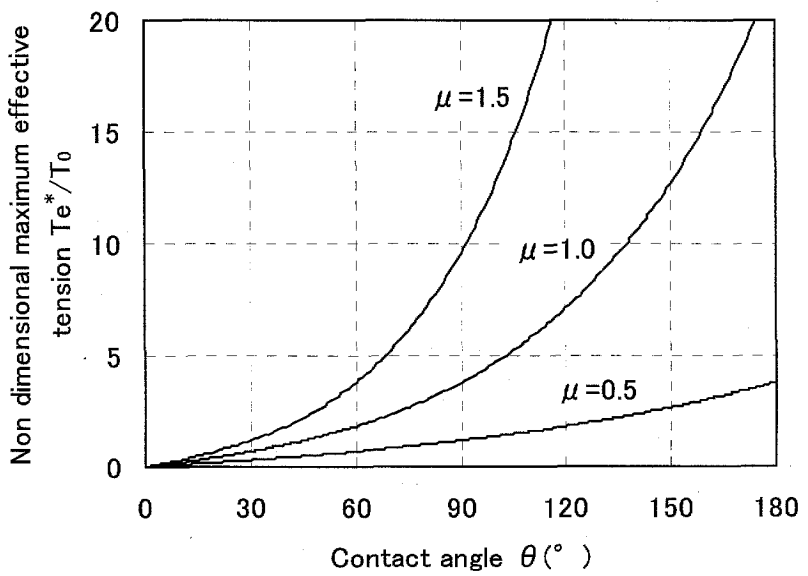

Fig. 3 Calculated results of maximum effective tension in case of DW located at the slack side.

\subsection{DWを張り側に配置した場合}

図 2 において，駆動軸を反時計回り（CCW）に回転させ るとDWは張り側配置となるが，この時，張り側，緩み側の 
張力比は次式で与えられる。

$$
T_{0} / T_{s}=e^{\mu \phi}
$$

また，この場合の有効張力は次式のようになる.

$$
T_{e}=T_{0}-T_{s}
$$

ここで, $T_{s}$ は緩み側張力， $T_{0}$ はDWによって決まる張り側 張力 (一定) である. 最大有効張力を記述のDW緩み側配置 の場合と同様にして式(4), 式(5)より求めると次式のように なる。

$$
T_{e}^{*}=\left(1-e^{-\mu \theta_{n}}\right) T_{0}
$$

式(6)による最大有效張力を巻き付け角, 摩擦係数をパラメ 一タに取り計算した結果を図 4 に示すが，式(6) からも明ら かなように最大有効張力は巻き付け角, 摩擦係数を幾ら大き くしても設定張力 $T_{0}$ を越えることはない.

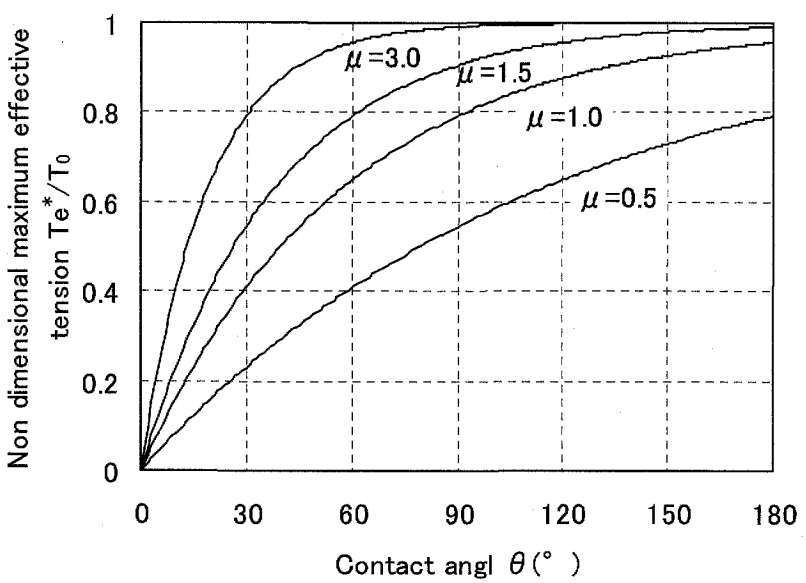

Fig.4 Calculated results of maximum effective tension in case of DW located at the tight side.

\section{3. 実験検証}

\section{1 DWを緩み側に配置した場合}

試験装置のレイアウトは図 2 に示す通りであり，供試べル

\begin{tabular}{|c|c|c|c|c|c|}
\hline \multirow{2}{*}{$\begin{array}{l}\text { Belts for } \\
\text { experiment }\end{array}$} & \multicolumn{2}{|c|}{ Contact angle } & \multicolumn{2}{|c|}{$\begin{array}{c}\text { Span length } \\
\text { (m) }\end{array}$} & \multirow{2}{*}{$\begin{array}{l}\text { Idler pulley } \\
\text { diameter } \\
(\mathrm{mm})\end{array}$} \\
\hline & $\theta_{r}$ & $\theta_{n}$ & $L_{1}$ & $L_{2}$ & \\
\hline $\mathrm{A}(5 \mathrm{PK} 1430)$ & 158 & 158 & 0.507 & 0.593 & 120 \\
\hline
\end{tabular}
トは表 1 に示すベルトを用いた。

Table 1 Experimental layout and calculation parameters

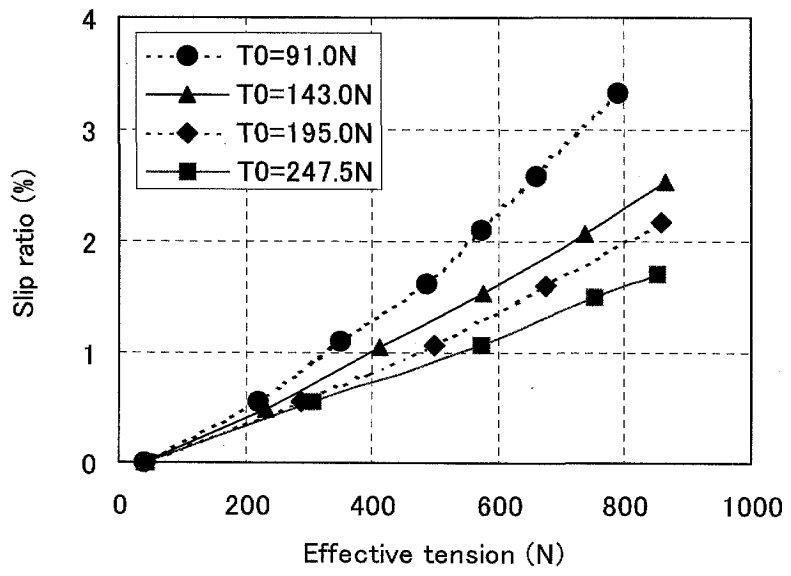

Fig. 5 Results of transmission performance experiments in case of DW located at the slack side.
$\mathrm{DW}$ 緩み側配置の荷重 $W$ (緩み側張力 $T_{0}$ ) は 8.7 Kgf $(91.0 \mathrm{~N})$, 13. $7 \mathrm{Kgf}(143.0 \mathrm{~N}), 18.7 \mathrm{Kgf}(195.0 \mathrm{~N}), 23.7 \mathrm{Kgf}(247.5 \mathrm{~N}) の 4$ 条件とした。試験結果を図 5 に示すが，スリップ率は有効張 力に対してほぼ直線に近い形で増加しており，固定の場合の ように 1\%〜2\%辺りを境にスリップ率が急上昇する様な傾 向は見られない. 試験に対忍した条件で式(3)により計算し た最大有効張力と試験結果の比較を図 6 に示す. 図中の実験 值は図 5 のデータの二次式による近似曲線より $2 \%$,及び $6 \%$ スリップ時の有效掁力を内、外挿したものである.

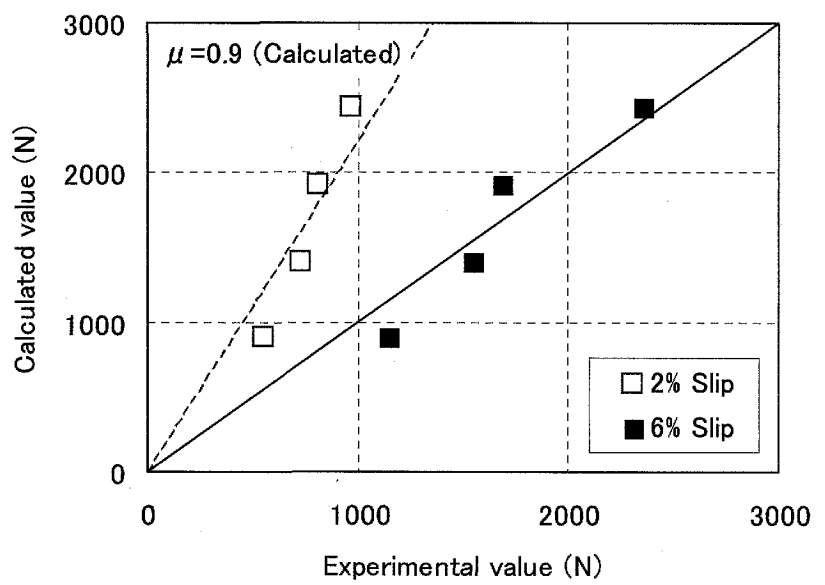

Fig.6 Comparison of experimental and calculated results.

プーリ固定の場合の最大有効張力計算值が $2 \%$ スリップ時の 実験值と良く対応したのに対して，DWを緩み側に配置した 場合の計算值は $6 \%$ スリップ時の実験値と比較的良く対応し ている，全滑りに至った時点，換言すれば弾性滑り限界のス リップ率 $S$ はベルトの引張り強さ $E A$ を用いて $S=T_{e}^{*} / E A$ で与えられ，有効張力に比例する．このことから，DWを緩 夕側に配置した場合の全滑りに至る有効張力, 即ち伝達性能 はプーリ固定の場合の約 3 倍であると推定される。なお，図 6 から明らかなように，緩み側DW配置における $2 \%$ スッッ プ時の伝達性能は計算值（或いは $6 \%$ スリップ時）の約 $1 / 2$ となっている. 従って, 上記のことから $2 \%$ スリップ時の伝 達性能で比較すると，DW緩み側配置の場合はプーリ固定の 場合の約 1.5 倍であると言える.

3.2 DWを張り側に配置した場合

$\mathrm{DW}$ 張り側配置の荷重 $W$ （緩み側張力 $T_{0}$ ) は $28.7 \mathrm{Kgf}$ (299.5N) としたが，この場合の試験結果を図 7 に示す. 有効

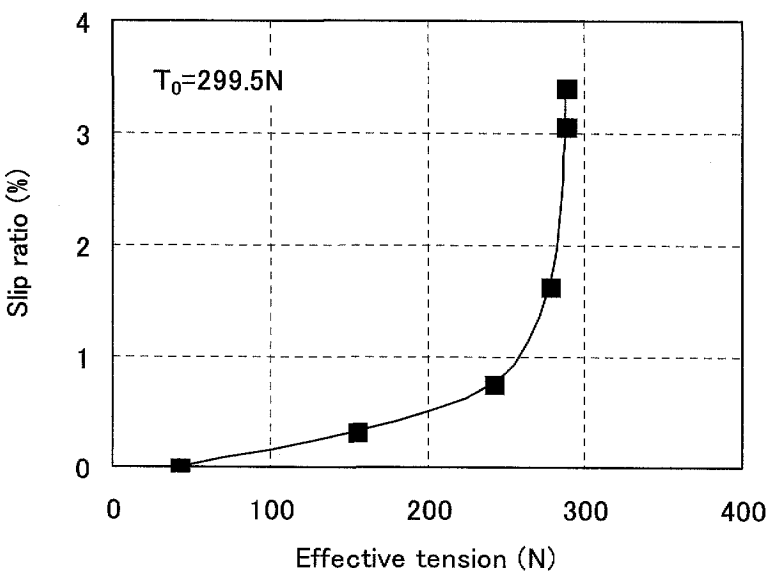

Fig.7 Results of transmission performance experiments in case of DW located at the tight side. 
張力はスリップ率 $2 \%$ 程度以上ではほぼ飽和状態を示し一定 值に漸近している.

試験に対応した条件で式 (6)により計算した最大有効張力と 試験における飽和状態の一定值との比較を図 8 に示すが，両 者は非常に良く一致している. 但し, 図 8 中には記述の試験 結果以外の類似試験の結果も併せて表示してある.

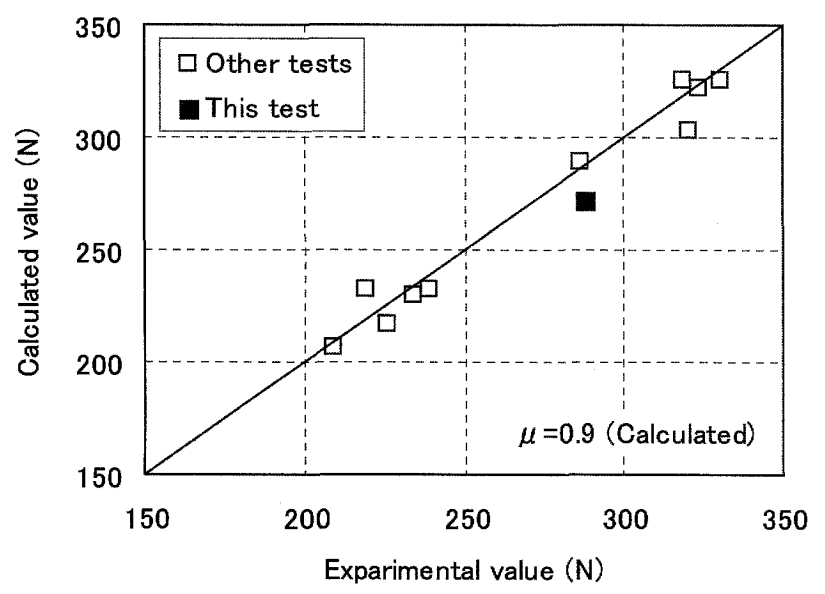

Fig.8 Comparison of experimental and calculated results.

4. プーリ固定と緩み側DWの伝達性能比較

図 2 に示すアイドラープーリ固定の場合の最大有効張力は 次式で与えられる ${ }^{(3)}$.

$$
T_{e}^{*}=\frac{\left(L_{s}+R_{n} \theta_{n}+L_{t}+R_{r} \theta_{r}\right)}{\left\{\frac{L_{s}+\left[L_{t}+R_{r}\left(\theta_{r}-\theta_{n}\right)\right] e^{\mu \theta_{n}}}{e^{\mu \theta_{n}}-1}+\frac{R_{r}+R_{n}}{\mu}\right\}} T_{0}
$$

また，図 2 のアイドラー軸にDWを緩み側に配置した場合の 最大有効張力は式 (3) で与えられる為, 固定に対するDWの 伝達性能比である最大有効張力比は次式のようになる.

$$
\frac{T_{e}^{D}}{T_{e}^{F}}=\left(e^{\mu \theta_{n}}-1\right) \frac{\left\{\frac{L_{s}+\left[L_{t}+R_{r}\left(\theta_{r}-\theta_{n}\right)\right] e^{\mu \theta_{n}}}{e^{\mu \theta_{n}}-1}+\frac{R_{r}+R_{n}}{\mu}\right\}}{\left(L_{s}+R_{n} \theta_{n}+L_{t}+R_{r} \theta_{r}\right)} \frac{T_{0}^{D}}{T_{0}^{F}}
$$

ここで, $T_{e}^{F}, T_{e}^{D}$ は固定，及びDWの場合の最大有効張力て あり， $T_{0}^{F} ， T_{0}^{D}$ は固定，及びDWの場合の設定張力である. 固定とDWの場合の伝達性能を一般的に比較するには式 (8) は少し複雑すぎる。 そこで $R_{r}=R_{n} \equiv R, \theta_{r}=\theta_{n} \equiv \theta$ ， $L_{t}=L_{s} \equiv L$ とし, 更に $R / L=0$ を仮定すると式(8) 次式 $\sigma$

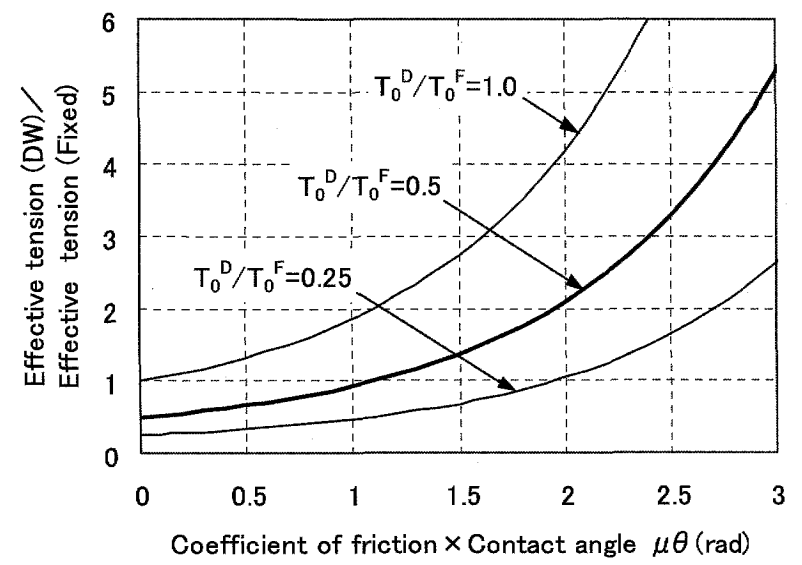

Fig.9 Transmission performance of DW system located at the slack side versus pulley fixed system.
ようになる。

$$
\frac{T_{e}^{D}}{T_{e}^{F}}=\frac{\left(e^{\mu \theta}+1\right)}{2} \frac{T_{0}^{D}}{T_{0}^{F}}
$$

式(9)を $\mu \theta$ に対して図示すると図 9 のようになる. 具体的 な例としてェンジン補機駆動用 Vリブドベルトについて考 えると，DWの場合の設定張力はプーリ固定の場合の略 $1 / 2$ であり, $T_{0}^{D} / T_{0}^{F}=0.5$ となる. また, 摩擦係数は 1.0 前後で あり，補機プーリの巻き付け角を $90^{\circ} \sim 180^{\circ}$ とすると $\mu \theta$ は 1.5 3.0 となる. 従って, 図 9 よりDW緩み側配置の場 合の伝達性能はプーリ固定の場合に比し概略 1.5〜 5. 0 倍, 平均的に見ると 3 倍程度向上することになるが，この結果は 記述の実験結果とも対応している. 因みに, 図 2 , 表 1 に示 すプーリ径, 巻き付け角, スパン長等のレイアウトパラメー 夕, 及び $\mu=0.9, T_{0}^{D} / T_{0}^{F}=0.5$ の值を用いて式(8) を計算 すると $T_{e}^{D} / T_{e}^{F}=2.84$ となる.

\section{5.まとめ}

（1）DWによる張力付与方式の場合の伝達性能に対応する 最大有効張力の計算式を誘導すると共に, その妥当性を実 験との比較で検証した.

（2）DWは伝達性能上，張り側でなく緩み側に配置すべきこ とが理論的に明らかになった。

（3）緩み側 DW配置の場合の伝達性能はプーリ固定に比し 約 3 倍となり, 同じ $2 \%$ スリップで比較すると約 1.5 倍と なることが分かった。

\section{参考文献}

（1）ベルト伝動技術笮話会 ; 新版 ベルト伝動・精密搬送の 実用設計，養賢堂，東京，(2006), pp. 92

（2）大倉 清, 龍巳良彦; 摩擦伝動ベルトの初期設定張力上 走行時張力の関係について, [No.06-1] 日本機械学会 2006 年度年次大会講演論文集 (4) [2006.9], pp.175

（3）大倉 清, 橋本康弘 : 摩擦伝動ベルトの伝達性能予測に ついて, [No.07-1] 日本機械学会 2007 年度年次大会講演論 文集 (4) [2007.9], pp.81 